\title{
The Application of Quadratic Bezier Curve on Rotational and Symmetrical Lampshade
}

\author{
Erny Octafiatiningsih, Imam Sujarwo \\ Mathematics Department, Science and Technology Faculty, Maulana Malik Ibrahim State Islamic \\ University of Malang
}

Email: erny.octafia1710@gmail.com, imamsoejarwo@gmail.com

\begin{abstract}
The procedure of constructing lampshade is through parameter merger and selection of Bezier surfaces shapeshifters; thus it produces perfect and varied sitting-lamp shades. Constructing sitting-lamp shades requires the study of the physical (lighting) and geometry aspects. In terms of geometry, the existed sittinglamp shade creation models is generally monotonous and constructed from objects pieces. In line with these problems, this research is divided into four stages: First, preparing the data to build a sitting-lamp shade. Second, technical studying to construct the symmetricity of the sitting-lamp shade shape. Third, constructing the parts of the sitting-lamp shade, namely the base, the main part, the roof. Fourth, constructing the complete sitting-lamp shade. The results of this research to obtain the procedures of constructing the sitting-lamp shade namely: First, dividing the major axis into three non-homogeneous sub segments. Second, constructing parts of the sitting-lamp shade namely the base, the main part, and the roof by combining the sitting-lamp shade components from the geometrical objects deformation. Third, filling each sub segment of non-homogeneous parts with parts of the lampshade and creating the boundary curves producing a varied innovative symmetrical models of sitting-lamp shade.
\end{abstract}

Keywords: sitting-lamp shade, Hermit curve, Bezier curve.

\section{INTRODUCTION}

The fabrication process of lampshade requires several treatments. First, building a model of the object to be constructed. Second, converting raw materials into semi-finished object. Third, forming semi-finished object to a subtler form. And the last, smoothing the surface of objects. The problem is that it turns out the existed design and fabrication techniques, often causes industry losses. First, using mall design technique that widely used by the craftsmen, the obtained results are often fails to meet the export contract orders, it is because the size of the object become incompatible with the buyer's order. Second, trial and error technique fabrication requires more expensive cost, since it produces many risks and errors on fabrications. It also requires extra time and effort for the production process. In addition, the lack of awareness of the manufactured object needs, many raw materials are wasted.

Constructing sitting-lamp shades requires the study of the physical (lighting) and geometry aspects. In terms of geometry, the existed sitting-lamp shade creation models is generally monotonous and constructed from objects pieces. It can be seen that the industrial sitting-lamp shade products are still simple and the used design techniques are still conventional. The technique takes a very long time so the customer orders are often not completed on time. 
Besides, the resulted products are generally constants, no improvements in terms of arts and innovations needed by customers. The diversity is in the form of the level of symmetricity, harmony, and model variations as well as from the types and sizes of the offered products.

This article is a scientific effort to obtain innovative and varied sitting-lamp shade models. This article attempts to construct a sitting-lamp shade, so that the procedure of its construction can be determined.

\section{THEORITICAL REVIEW}

\section{Quadratic Hermitian Curve}

The Hermitian curve is in the form of

with

$$
P(u)=P(0) K_{1}(u)+P(1) K_{2}(u)+P^{\prime}(1) K_{3}(u)
$$

$K_{1}(u)=\left(1-2 u+u^{2}\right)$

$K_{2}(u)=\left(2 u-u^{2}\right)$

$K_{3}(u)=\left(-u+u^{2}\right)$

$P(0)=$ initial point of the curve in the form of $\left(x_{0}, y_{0}, z_{0}\right)$

$P(1)=$ end point of the curve in the form of $\left(x_{1}, y_{1}, z_{1}\right)$

$P^{\prime}(1)=$ control point of curvature of the curve with $0 \leq u \leq 1[1]$

\section{Second Order Bezier Curve}

The second order Bezier curve is represented in parametric form:

with $0 \leq u \leq 1[2]$.

$$
V(u)=K_{0}\left(1-2 u+u^{2}\right)+K_{1}\left(2 u-2 u^{2}\right)+K_{2}\left(u^{2}\right)
$$

\section{Rotation}

Rotation is the change of an object coordinates into the new position by moving the whole point coordinates defined in the initial form with an angle on an axis of rotation. The coordinate system $R^{3}$ has three rotary axes, the rotation of each axis can be written as follows, with $\theta$ denotes the rotary angle.

a. Rotation on $x$-axis

$$
\left(x_{q}, y_{q}, z_{q}\right)=\left(x_{p}, y_{p} \cdot \cos \theta-z_{p} \cdot \sin \theta, y_{p} \cdot \sin \theta+z_{p} \cdot \cos \theta\right)
$$

b. Rotation on $y$-axis

$$
\left(x_{q}, y_{q}, z_{q}\right)=\left(x_{p} \cdot \cos \theta+z_{p} \cdot \sin \theta, y_{p} x_{p} \cdot(-\sin \theta)+z_{p} \cdot \cos \theta\right)
$$

c. Rotation on $z$-axis

$$
\left(x_{q}, y_{q}, z_{q}\right)=\left(x_{p} \cdot \cos \theta+y_{p} \cdot \sin \theta, x_{p} \cdot(-\sin \theta)+y_{p} \cdot \cos \theta, z_{p}\right)
$$

[3]

\section{Displacement}

If $P\left(x_{p}, y_{p}, z_{p}\right)$ is the initial position, $Q\left(x_{q}, y_{q}, z_{q}\right)$ is the position after point is displaced, $I$ is the identity matrix, and $\left(t r_{x}, t r_{y}, t r_{z}\right)$ is a constant value that indicates the amount of displacement in each coordinate axes, then the displacement can be expressed as[3]

$$
\left(x_{q}, y_{q}, z_{q}\right)=\left(x_{p}+t r_{x}, y_{p}+t r_{y}, x_{p}+t r_{x}\right)
$$




\section{Interpolation of Line Segments and Curves in Space}

Let $\overline{A B}$ and $\overline{C D}$ be line segments defined by: $A\left(x_{1}, y_{1}, z_{1}\right), B\left(x_{2}, y_{2}, z_{3}\right), C\left(x_{3}, y_{3}, z_{3}\right)$ and $D\left(x_{4}, y_{4}, z_{4}\right)$ in parametrical form $I_{1}(u)$ and $I_{2}(u)$. Parametrical surface obtained from linear interpolation of to line segments is formulated as follows

With $0 \leq u \leq 1$ and $0 \leq v \leq 1$.

$$
S(u, v)=(1-v) I_{1}(u)+v I_{2}(u)
$$

There are special cases of linear interpolations form of these two line segments. If $A=B$, then the interpolation result of (7) produces a triangle. If $\overline{A B} \| \overline{C D}$, then it is generally produces a quadrangle plane. If the plane is obtained from interpolation of two crossed lines, then it produces a non-flat surface (can be curved of twisted) in some regions of the surface.[4]

Curved surfaces can be constructed from space curve interpolations using the following equation

$$
S(u, v)=(1-v) C_{1}(u)+v C_{2}(u)
$$

where $C_{1}(u)$ and $C_{2}(u)$ are boundary curves (Figure 2)[4]

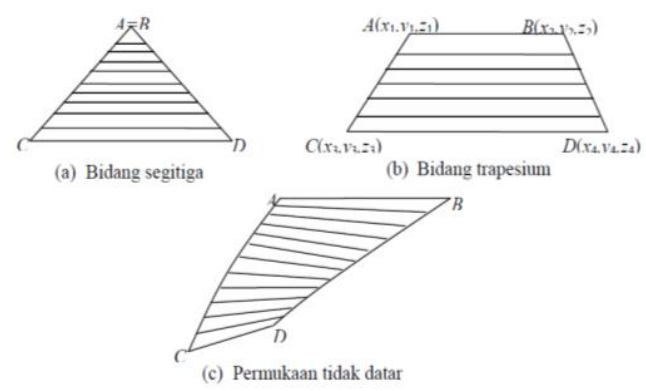

Figure 1. Special case of Linear Interpolation of two line segments

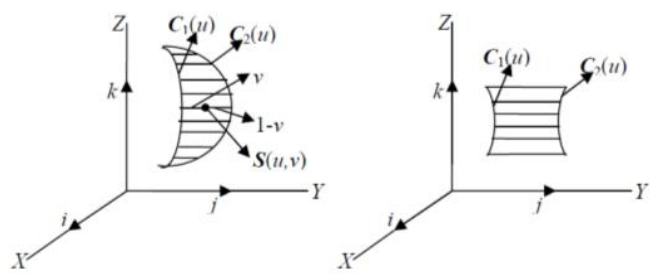

Figure 2. A linear interpolation on curves

\section{Point Dilatation on $\mathbb{R}^{3}$}

Dilatations that maps point $P(x, y, z)$ to $P^{\prime}\left(x^{\prime}, y^{\prime}, z^{\prime}\right)$ is formulated to:

$$
\left[\begin{array}{l}
x^{\prime} \\
y^{\prime} \\
z^{\prime}
\end{array}\right]=\left[\begin{array}{ccc}
k_{1} & 0 & 0 \\
0 & k_{2} & 0 \\
0 & 0 & k_{3}
\end{array}\right]\left[\begin{array}{l}
x \\
y \\
z
\end{array}\right]
$$

In this case $k_{1}, k_{2}, k_{3}$ represent the scale factors on $X$-axis, $Y$-axis, and $Z$-axis respectively. If $k_{1}=k_{2}=k_{3}$, then the resulting objects are congruent with the original objects (enlarged, reduced, or remain unchanged).[1]

For instance, a triangle $P Q R$ with angle points $P\left(x_{1}, y_{1}, z_{1}\right), Q\left(x_{2}, y_{2}, z_{2}\right)$ and $R\left(x_{3}, y_{3}, z_{3}\right)$ is dilated with multiplication factor $k>1$, then we obtain triangular map $P^{\prime} Q^{\prime} R^{\prime}$ with angle points $P^{\prime}\left(k x_{1}, k y_{1}, k z_{1}\right), Q^{\prime}\left(k x_{2}, k y_{2}, k z_{2}\right)$ and $R^{\prime}\left(k x_{3},{ }^{9} y_{3}, k z_{3}\right)$ showed in Figure 3. 


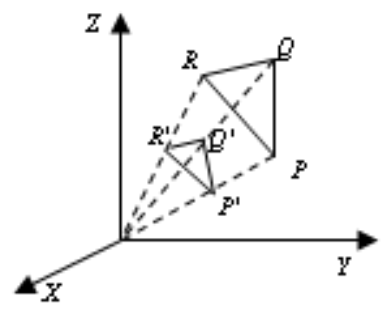

Figure 3. Second order Bezier curve

\section{The Representation of Geometry Space Objects}

a. Representation of a tube

Let a tube is known with the base center $P_{1}\left(x_{1}, y_{1}, z_{1}\right)$, radius $r$, and height $t$, it can be drawn using the following equations:

If the central axis is parallel to $Z$-axis

$$
T(\theta, z)=\left(x_{1}+r \cos \theta, y_{1}+r \sin \theta, z\right)
$$

with $0 \leq \theta \leq 2 \pi$ and $r \in \mathbb{R}$.

If the central axis is parallel to $X$-axis

$$
T(\theta, z)=\left(x, y_{1}+r \sin \theta, z_{1}+r \cos \theta\right)
$$

with $0 \leq \theta \leq 2 \pi$ and $x_{1}<x \leq x_{1}+t$.

If the central axis is parallel to $Y$-axis

$$
T(\theta, z)=\left(x_{1}+r \cos \theta, y, z_{1}+r \sin \theta\right)
$$

with $0 \leq \theta \leq 2 \pi$ and $y_{1} \leq y \leq y_{1}+t$. [5]

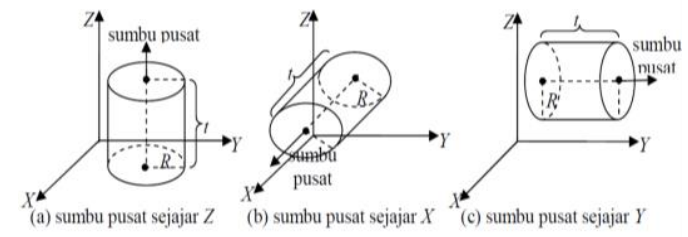

Figure 4. Tubes with different central axis

b. Representation of a ball

A ball with center $Q(a, b, c)$ and radius $r$ is formulated to:

$$
B(\theta, \beta)=(r \sin \theta \cos \beta+a, r \cos \theta+c, r \sin \theta \sin \beta+b)
$$

with parameter $0 \leq \theta \leq 2 \pi$ and $0 \leq \beta \leq 2 \pi[5]$.

\section{RESULTS AND DISCUSSION}

This article describes the procedures of constructing the sitting-lamp shade. The first procedure is to construct the used components of siting-lamp shade. The next step is to construct parts of the sitting-lamp shade namely the base, and the main part of the roof. The latter procedure is to construct the full sitting-hood.

A. Constructing sitting-lamp shade components

1. Tube deformation

Suppose given a tube of radius $r$, the minimum radius of the tube is $10 \mathrm{~cm}$, while the maximum limit of the tube radius is $20 \mathrm{~cm}$, the minimum height tube is $10 \mathrm{~cm}$ while the maximum height of the tube is $30 \mathrm{~cm}$, and the base is centered in $P\left(x_{0}, y_{0}, z_{0}\right)$. Thus, the sizes of the tube is $10 \mathrm{~cm} \leq t \leq 30 \mathrm{~cm}$ and $10 \mathrm{~cm} \leq r \leq 20 \mathrm{~cm}$. The selection of the value of $r$ and $t$ in the interval aims to differences in size of shape components of sittinglamp shade. Based on these data designed various forms of constituent components of the sitting-lamp shade using surface curve modification techniques and surface arch dilatation technique. as follows:

The algorithms of tube deformation with the modification of the surface curve are 
a. Determined a center point on the tube base circle $\left(x_{1}, y_{1}, z_{1}\right)=(0,0,0)$, build the tube base circle using the circle equation and set the value $\theta=0$ and obtain the point $P(0)$.

$$
\begin{aligned}
P(0) & =\left(x_{1}+r_{1} \cos \theta, y_{1}+r_{1} \sin \theta, z_{1}\right) \\
& =\left(r_{1}, 0,0\right) .
\end{aligned}
$$

b. Determined center point on the tube roof circle namely $\left(x_{1}, y_{1}, z_{1}\right)=(0,0, t)$, build tube roof circle using the circle equation and set the value $\theta=0$ and obtain one point, namely $P(1)$.

$$
\begin{aligned}
P(1) & =\left(x_{1}+r_{2} \cos \theta, y_{1}+r_{2} \sin \theta, z_{1}\right) \\
& =\left(r_{2}, 0, t\right) .
\end{aligned}
$$

c. Determined control point $P^{\prime}(1)$ to control the curvature of the Hermit curve so that with $-2 r \leq x, z \leq 2 t$ and $x, z \in R$.

$$
P^{\prime}(1)=(x, 0, z)
$$

d. Hermit curve constructed by substituting value $P(0), P(1)$ and $P^{\prime}(1)$ to the equation (1) thus obtained

$$
\begin{gathered}
P(u)=\left(r H_{1}(u)+r H_{2}(u)+x H_{3}(u), 0 H_{1}(u)+0 H_{2}(u)+0 H_{3}(u), 0 H_{1}(u)\right. \\
\left.+t H_{2}(u)+z H_{3}(u)\right)
\end{gathered}
$$

with

$$
\begin{aligned}
& H \_1(u)=\left(1-u-u^{\wedge} 2\right) \\
& H \_2(u)=\left(2 u-u^{\wedge} 2\right) \\
& H \_3(u)=\left(-u+u^{\wedge} 2\right) \\
& 0 \leq u \leq 1 .
\end{aligned}
$$

e. Hermit curve is rotated about the $Z$ axis using equation (5) and $0 \leq \theta \leq 360^{\circ}$ so that

$$
\begin{gathered}
P(u)=\left(\left(r H_{1}(u)+r H_{2}(u)+x H_{3}(u)\right) \cos \theta,\left(r H_{1}(u)+r H_{2}(u)\right.\right. \\
\left.\left.+x H_{3}(u)\right) \sin \theta, 0 H_{1}(u)+t H_{2}(u)+t H_{3}(u)\right)
\end{gathered}
$$
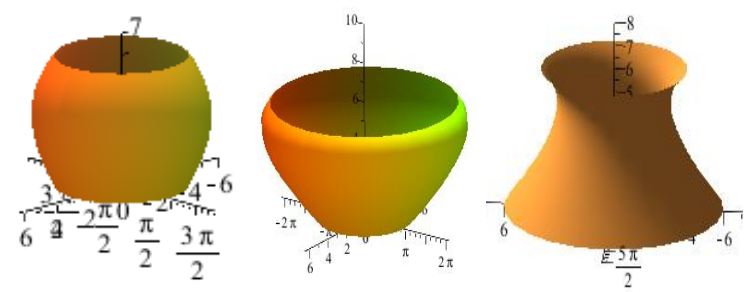

Figure 5. different results of tube deformations

2. Hexagonal prism deformation

Suppose given a regular hexagonal prism with coordinate pairs $\left[K_{i}\left(x_{i}, y_{i}, z_{i}\right), K_{i}^{\prime}\left(x_{i}, y_{i}, z_{i}+t\right)\right]$ with $i=1,2,3, \ldots, 6$ and $t 5 \mathrm{~cm} \leq t \leq 15 \mathrm{~cm}$. All of its closure has center of gravity on $K\left(x_{0}, y_{0}, z_{0}\right)$ and $K^{\prime}\left(x_{0}, y_{0}, z_{0}+t\right)$. The distance of $K$ to $K_{I}$ and $K^{\prime}$ to $K_{i}^{\prime}$ is $6 \mathrm{~cm} \leq r \leq 10 \mathrm{~cm}$. In this case, $\overline{K K^{\prime}}$ is taken as the axis of symmetry of hexagonal prism deformation.

Steps of straight side deformation of the prism into curved-concaved namely:

a. Determined $K_{i}$ and $K_{i}^{\prime}$ with $i=0,1,2,3,4,5$ as a control point for multiple Bezier curves using the linear equation of the circle by setting $\theta=\frac{i \pi}{3}$ and $\left(x_{1}, y_{1}, z_{1}\right)=$ $(0,0,0)$.

$$
\begin{aligned}
& K_{i}(\theta)=\left(r \cos \frac{i \pi}{3}, r \sin \frac{i \pi}{3}, 0\right) \\
& K_{i}^{\prime(\theta)}=\left(r \cos \frac{i \pi}{3}, r \sin \frac{i \pi}{3}, t\right) .
\end{aligned}
$$

b. Defined control points $Q$ to control the curvature of the quadratic Bezier curve 


$$
Q=\left(x_{0}, y_{0}, z\right) \text { with } z \in\left[z_{0}, t\right] \text {. }
$$

c. Bezier curve of degree two for each pair of control points $\left(K_{i}, Q, K_{i}^{\prime}\right)$ is built using the equation (2)

with $0 \leq u \leq 1$.

$$
V_{i}(u)=(1-u)^{2} K_{i}+2(1-u)(u) Q+u^{2} K_{i}^{\prime}
$$

d. Bezier curves are consecutively linearly interpolated in pairs using equation (8) counter clockwise

$$
\begin{aligned}
& \mathrm{S}(\mathrm{u}, \mathrm{v})=\left((1-v)(1-u)^{2} r \cos \frac{i \pi}{3}+(1-v)\left(2 u-2 u^{2}\right) x_{0}+(1-v) u^{2} r \cos \frac{i \pi}{3}+\right. \\
& v(1-u)^{2} r \cos \frac{(i+1) \pi}{3}+v\left(2 u-2 u^{2}\right) x_{0}+v u^{2} r \cos \frac{(i+1) \pi}{3},(1-v)(1-u)^{2} r \sin \frac{i \pi}{3}+ \\
& (1-v)\left(2 u-2 u^{2}\right) y_{0}+(1-v) u^{2} r \sin \frac{i \pi}{3}+v(1-u)^{2} r \sin \frac{(i+1) \pi}{3}+v\left(2 u-2 u^{2}\right) y_{0}+ \\
& v u^{2} r \sin \frac{(i+1) \pi}{3},(1-v)(1-u)^{2} 0+(1-v)\left(2 u-2 u^{2}\right) z+(1-v) u^{2} 0+v 0(1- \\
& \left.u)^{2}+v\left(2 u-2 u^{2}\right) z+v 0 u^{2}\right) \\
& \text { with } 0 \leq v \leq 1 \text { and } 0 \leq u \leq 1 .
\end{aligned}
$$
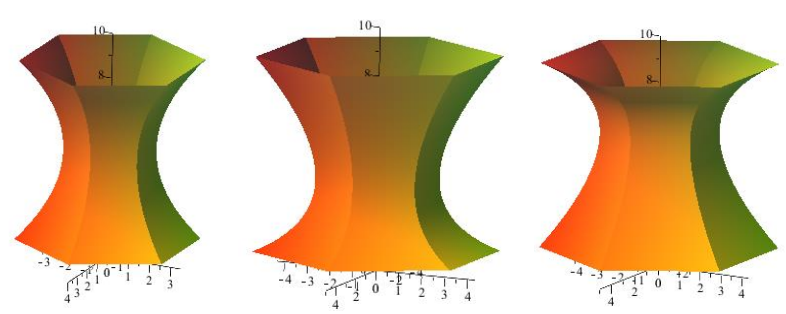

Figure 6. Variety of tube deformation

\section{B. Constructing full lampshade}

Furthermore, to obtain an intact form of sitting-lamp shade combined continuously in this section the concatenation of several basic components of sitting-lamp shade by combining the components parts of the sitting-lamp shade is conducted.

Steps of constructing full sitting-lamp shade:

1. The part of the line segment $\overline{S_{3} S_{4}}$ is filled with the base shade component of sitting-lamp.

2. The part of the line segment $\overline{S_{2} S_{3}}$ is filled with the main part of the sitting-lamp shade and adjust its height.

3. The part of the line segment $\overline{S_{2} S_{1}}$ is filled with the roof parts and adjust the sitting-lamp shade height.

4. Some parts sitting-lamp shade is combined by establishing the boundary between two adjacent components with the following procedures.

a. Defined circle or a regular hexagon as a cap of the sitting-lamp shade base component with radius $r_{1}$ as boundary curve $C_{1}(u)$.

b. Defined circle or a regular hexagon as an upper cap of the sitting-lamp shade of the main components with radius $r_{2}$ as boundary curve $C_{2}(u)$.

c. The boundary between $C_{1}(u)$ and $C_{2}(u)$ is constructed using linear interpolation of equation (8).

d. Do steps (a) to (c) to establish the boundary between the main body of the sitting-lamp shade with roofing components. 


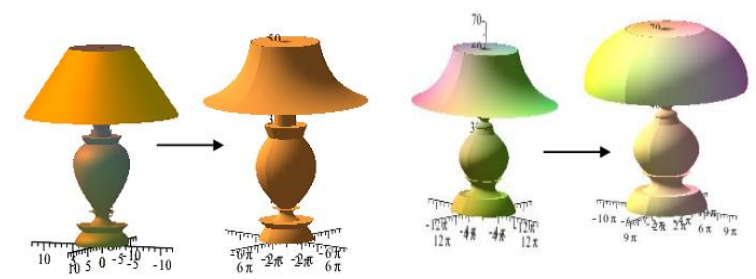

Figure 7. Another variety of sitting-lamp shade with different control points

\section{REFERENCE}

[1] Kusno, Geometri Rancang Bangun Studi Tentang Desain dan Pemodelan Benda dengan Kurva dan Permukaan Berbantu Komputer, Jember: Jember University Press, 2010.

[2] Kusno, A. Cahaya and M. Darsin, "Modelisasi Benda Onyx dan Marmer Melalui Penggabungan dan Pemilihan Parameter Pengubah Bentuk Permukaan Putar Bezier," Jurnal Ilmu Dasar, pp. 175-185, 2014.

[3] A. Cristiyyanto, "Perancangan Objek Tiga Dimensi dengan Teknik Flat Shading dan Gouraund Menggunakan Bahasa Turbo Pascal 7.0," Skripsi tidak dipublikasikan, 2003.

[4] M. Roifah, "Modelisasi Knop Melalui Penggabungan Benda Dasar Hasl Deformasi Tabung, Prisma Segienam Beraturan dan Permukaan Putar," Skripsi tidak dipublikasikan, 2013.

[5] A. Bastian, "Desain Kap LAmpu Duduk Melalui Penggabungan Benda-benda Geometi Ruang," Skripsi tidak dipublikasikan, 2010. 